\title{
IL-33 can promote survival, adhesion and cytokine production in human mast cells
}

\author{
Motoyasu likura, ${ }^{1,2}$, Hajime Suto ${ }^{1,3}$, Naoki Kajiwara ${ }^{4}$, Keisuke Oboki ${ }^{5}$, Tatsukuni Ohno ${ }^{5}$, Yoshimichi Okayama ${ }^{4}$, \\ Hirohisa Saito ${ }^{3,5}$, Stephen J Galli ${ }^{1}$ and Susumu Nakae ${ }^{1,3,5}$
}

IL-33 is a recently identified member of the IL- 1 family of molecules, which also includes IL- 1 and IL-18. IL-33 binds to the receptor, T1/ST2/IL-1R4, and can promote cytokine secretion by Th2 cells and NF- $\kappa$ B phosphorylation in mouse mast cells. However, the effects of these molecules, especially IL-33, in human mast cells are poorly understood. Expression of the receptors for IL-1 family molecules, specifically, IL-1R1, IL-18R and T1/ST2, was detectable intracellularly in human umbilical cord blood-derived mast cells (HUCBMCs) by flow cytometry, but was scarcely detectable on the cells' surface. However, IL-1 $\beta$, IL-18 or IL-33 induced phosphorylation of Erk, p38 and JNK in naïve HUCBMCs, and IL-33 or IL-1 $\beta$, but not IL-18, enhanced the survival of naive HUCBMCs and promoted their adhesion to fibronectin. IL-33 or IL-1 $\beta$ also induced IL-8 and IL-13 production in naïve HUCBMCs, and enhanced production of these cytokines in IgE/anti-lgE-stimulated HUCBMCs, without enhancing secretion of either $\mathrm{PGD}_{2}$ or histamine. Moreover, IL-33-mediated IL-8 production by HUCBMCs was markedly reduced by the p38 MAPK inhibitor, SB203580. In contrast to findings with mouse mast cells, IL-18 neither induced nor enhanced secretion of the mediators $\mathrm{PGD}_{2}$ or histamine by HUCBMCs. Our findings identify previously unknown functions of IL-33 in human mast cells. One of these is that IL-33, like IL-1 $\beta$, can induce cytokine production in human mast cells even in the absence of stimuli of $\mathrm{Fc} \varepsilon \mathrm{RI}$ aggregation. Our findings thus support the hypothesis that IL-33 may enhance mast cell function in allergic disorders and other settings, either in the presence or absence of co-stimulation of mast cells via IgE/antigen-FceRl signals.

Laboratory Investigation (2007) 87, 971-978; doi:10.1038/labinvest.3700663; published online 13 August 2007

KEYWORDS: allergy; human umbilical cord blood-derived mast cells; IL-1; IL-18; Th2

Mast cells can have important effector functions in both innate and adaptive immune responses. ${ }^{1,2}$ In IgE-associated allergic disorders, and during infections with certain parasites, crosslinking of IgE bound to the high-affinity IgE receptor (FceRI) on mast cells by multivalent antigens (Ags) promotes $\mathrm{Fc} \varepsilon \mathrm{RI}$ aggregation, which in turn triggers mast cell activation and the secretion of various pro-inflammatory mediators, cytokines and growth factors ${ }^{3-9}$

In vitro studies have shown that certain pro-inflammatory cytokines, including IL-1, can enhance IgE/Ag-FceRI-mediated activation, including the secretion of Th2-type cytokines, in human ${ }^{10}$ and mouse ${ }^{11,12}$ mast cells. Like IL-1, IL-18 can promote IL-13 production by mouse mast cells and basophils in the presence of IL-3. ${ }^{13}$ However, the IL-1 family of cytokines consists of at least 10 molecules, including six newly identified molecules named IL-1F5-10, in addition to the classic IL-1 molecules, IL- $1 \alpha / \mathrm{IL}-1 \mathrm{~F} 1, \mathrm{IL}-1 \beta / \mathrm{IL}-1 \mathrm{~F} 2, \mathrm{IL}-1$ receptor antagonist/IL-1F3 and IL-18/IL-1F4. ${ }^{14}$ An additional (eleventh) IL-1-related molecule, IL-33/IL-1F11, which is a ligand for T1/ST2/IL-1R4, has recently been identified. ${ }^{15} \mathrm{~T} 1 /$ ST2/IL-1R4 is preferentially expressed on Th2 cells ${ }^{16}$ and mast cells ${ }^{17}$ in the mouse, and IL-33 can promote the production of IL-4, IL-5 and IL-13 by mouse Th2 cells and can induce NF- $\kappa \mathrm{B}$ phosphorylation and MAP kinase activation in mouse mast cell lines. ${ }^{15}$

These observations indicate that members of the IL-1 family, including IL-1, IL-18 and IL-33, can enhance some mast cell functions, at least in the mouse. However, the effects of

\footnotetext{
'Department of Pathology, Stanford University School of Medicine, Stanford, CA, USA; ${ }^{2}$ Department of Respiratory Medicine, National Disaster Medical Center of Japan, Tokyo, Japan; ${ }^{3}$ Atopy Research Center, Juntendo University, Tokyo, Japan; ${ }^{4}$ Division of Molecular Cell Immunology and Allergology, Advanced Medical Research Center, Nihon University Graduate School of Medical Sciences, Tokyo, Japan and ${ }^{5}$ Department of Allergy and Immunology, National Research Institute for Child Health and Development, Tokyo, Japan

Correspondence: SJ Galli, MD, Department of Pathology, L-235, Stanford University School of Medicine, 300 Pasteur Drive, Stanford, CA 94305-5324, USA.

E-mail: sgalli@stanford.edu or S Nakae, PhD, Department of Allergy and Immunology, National Research Institute for Child Health and Development, 2-10-1 Okura, Setagaya-ku, Tokyo 157-8535, Japan. E-mail: snakae@nch.go.jp

Received 10 April 2007; revised 11 July 2007; accepted 11 July 2007
} 
members of the IL-1 family of cytokines on human mast cells remain poorly understood. For example, it is unknown whether human mast cells express IL-18R $\alpha$ or T1/ST2/IL1R4, or whether IL-18 or IL-33 can enhance human mast cell function.

In the present study, we found that either IL-33 or IL-1 $\beta$ promoted survival, adhesion to fibronectin and IL-8 and IL-13 secretion in human umbilical cord blood-derived mast cells (HUCBMCs). By contrast, neither IL- $1 \beta$ and IL-18, nor IL-33 induced HUCBMCs to secrete histamine or $\mathrm{PGD}_{2}$.

\section{MATERIALS AND METHODS}

\section{Human Umbilical Cord Blood-Derived Mast Cells}

HUCBMCs were obtained as described previously; ${ }^{18}$ the purity of all the preparations tested was $\sim 95 \%$ by FACS analysis. For in vitro studies, cells were washed and suspended in recombinant cytokine-free-RPMI1640 medium containing $10 \%$ fetal calf serum (FCS). Umbilical cord blood specimens were collected with the approval of the Ethical Review Boards of Stanford University, or of the National Research Institute for Child Health and Development in Japan.

\section{GeneChip ${ }^{\circledR}$ Expression Analysis}

Human genome-wide gene expression was examined with the Human Genome U133A probe array (GeneChip ${ }^{\circledR}$, Affymetrix, Santa Clara, CA, USA), according to the manufacturer's protocol (Affymetrix) and previous reports. ${ }^{19}$ Assessment of gene expression levels and data analysis were performed as previously described. ${ }^{19}$

\section{Flow Cytometry}

To assess expression of cell surface molecules, we incubated HUCBMCs with human IgG for $15 \mathrm{~min}$ on ice, and then added rat mAb anti-human IL-1R1/CD121a mAb (PBL Biomedical Laboratories, Piscataway, NJ, USA), biotinylated anti-T1/ST2/IL-1R4 mAb (MD Biosciences, Zurich, Switzerland), PE-conjugated anti-IL-18R $\alpha /$ IL-1R5 mAb (R\&D Systems, Minneapolis, MN, USA), or isotype-matched control IgG mAb in HBSS buffer containing 2\% inactivated FCS for $40 \mathrm{~min}$ on ice. After washing, the cells were stained with FITC-conjugated mouse anti-rat IgG2a (BD PharMingen, San Jose, CA, USA) and APC-conjugated streptavidin (BD PharMingen) for $30 \mathrm{~min}$. We analyzed the expression of IL-1R1, T1/ST2 or IL-18R $\alpha$ on 7-aminoactinomycin C-negative HUCBMCs using a FACSCalibur with CellQuest software (Becton Dickinson, San Jose, CA, USA). To assess the expression of intracellular molecules, we fixed cells in PBS containing $1.6 \%$ paraformaldehyde for $10 \mathrm{~min}$ at room temperature, permeabilized the cells in cold $100 \%$ methanol for $10 \mathrm{~min}$, washed them with HBSS buffer containing $2 \%$ FCS, and stained them with anti-human IL-1R1, T1/ST2, IL-18R $\alpha$ or isotype-matched control IgG mAb, as described above.

\section{Western Blotting}

Naïve HUCBMCs $\left(1 \times 10^{6}\right.$ cells $)$ were cultured in RPMI1640 medium containing $10 \%$ FCS and $100 \mathrm{ng} / \mathrm{ml}$ of rhIL-18 (MBL, Nagoya, Japan), rhIL-1 $\beta$ (PeproTech or R\&D systems) or rhIL-33 (AdipoGen, Seoul, South Korea or R\&D systems) at $37^{\circ} \mathrm{C}$ for $0,5,10$ or $15 \mathrm{~min}$. We then solubilized the cells by boiling in SDS sample buffer, separated the cell lysates by SDS-PAGE, electroblotted them onto Invitrolon PVDF membranes (Invitrogen, Carlsbad, CA, USA), and then probed with antibodies against phospho-Erk1/2 (E10; Cell Signaling Technology, Danvers, MA, USA), phospho-p38 (Cell Signaling Technology), phospho-JNK (Cell Signaling Technology) or GAPDH (Research Diagnostics Inc., Flanders, NJ, USA) at $4^{\circ} \mathrm{C}$ overnight. The membranes were then incubated with HRPO-Ab at room temperature for $1 \mathrm{~h}$, and visualized using ECL plus.

\section{Cell Survival}

We cultured naïve HUCBMCs $\left(5 \times 10^{5}\right.$ cells $)$ in RPMI 1640 medium containing $10 \%$ FCS and $100 \mathrm{ng} / \mathrm{ml}$ rhIL-18, rhIL$1 \beta$ or rhIL-33 at $37^{\circ} \mathrm{C}$ for $0,6,12,24$ or $48 \mathrm{~h}$. Live cells were counted under a microscope after trypan blue staining. Mast cell apoptosis was assessed by flow cytometry after double staining with FITC-conjugated annexin- $\mathrm{V}$ and propidium iodide (BD PharMingen, San Jose, CA, USA), in which we regarded propidium iodide-negative, annexin-V-positive cells as being apoptotic.

\section{Cell Adhesion}

We coated human fibronectin (Sigma, St Louis, MO, USA) at $10 \mu \mathrm{g} / \mathrm{ml}$ in PBS onto 96-well Maxisorp plates (Nunc, Rochester, NY, USA) at $4^{\circ} \mathrm{C}$ overnight. HUCBMCs ( 1 million cells $/ \mathrm{ml}$ ) were incubated with $3 \mu \mathrm{g} / \mathrm{ml}$ of calcein-AM (Invitrogen-Molecular Probes) at $37^{\circ} \mathrm{C}$ for $20 \mathrm{~min}$. After washing twice, we resuspended the cells in $0.03 \%$ BSA HBSS then added them to plates, which had been washed three times with PBS. We then incubated the cells with $100 \mathrm{ng} / \mathrm{ml}$ of rhIL-18, rhIL-1 $\beta$ or rhIL-33, in the presence or absence of SCF (100 ng/ml, Amgen, Thousand Oaks, CA, USA) at $37^{\circ} \mathrm{C}$ for $1.5 \mathrm{~h}$. The fluorescence of the samples was measured both before and after washing the plates, using a fluorescence plate reader at an excitation wavelength of $485 \mathrm{~nm}$ and emission wavelength of $520 \mathrm{~nm}$.

\section{HUCBMC Stimulation and Measurement of Secreted Mediators and Cytokines}

We cultured naive HUCBMCs (at $1 \times 10^{6}$ cells $/ \mathrm{ml}$ ) in RPMI1640 medium containing 10\% FCS in the presence or absence of $10 \mu \mathrm{g} / \mathrm{ml}$ of IgE (OEM concepts, Toms River, NJ, USA), with or without rhIL- $\beta$, rhIL-18 or rhIL-33 at $37^{\circ} \mathrm{C}$ for $1 \mathrm{~h}$ (for $\mathrm{PGD}_{2}$ and histamine release) or $24 \mathrm{~h}$ (for cytokine release). To assess the role of $\mathrm{p} 38 \mathrm{MAPK}$ in cytokine-induced secretion of IL-8, naïve HUCBMCs $\left(1 \times 10^{6}\right.$ cells $\left./ \mathrm{ml}\right)$ were stimulated with $100 \mathrm{ng} / \mathrm{ml} \mathrm{rhIL-1} \beta$ or rhIL-33, in the presence or absence of the p38 MAPK inhibitor, SB203580 
(JENA Bioscience, Jena, Germany). We solubilized SB203580 in $99.7 \%$ dimethyl sulfoxide (DMSO; SIGMA) as the stock solution $(100 \mathrm{mM})$, then diluted that in RPMI1640 supplemented with $10 \%$ FCS so that, after addition to cell suspensions $30 \mathrm{~min}$ before their stimulation with rhIL-1 $\beta$ or rhIL-33, the final concentrations of DMSO were $0.01,0.003$ or $0.001 \%$ for tests of SB203580 at 10,3 or $1 \mu \mathrm{M}$, respectively. ${ }^{20}$ The HUCBMCs were sensitized with 1 or $5 \mu \mathrm{g} / \mathrm{ml}$ of $\mathrm{IgE}$ at $37^{\circ} \mathrm{C}$ for $4 \mathrm{~h}$, and then were washed and cultured in the presence or absence of $1 \mu \mathrm{g} / \mathrm{ml}$ of anti-human IgE (Sigma), with or without rhIL- $1 \beta$, rhIL- 18 or rhIL- 33 at $37^{\circ} \mathrm{C}$ for 1 or $24 \mathrm{~h}$. To measure the amounts of histamine, $\mathrm{PGD}_{2}$ and IL-8 in the culture supernatants, we used the Histamine ELISA kit, $\mathrm{PGD}_{2}$ MOX EIA kit and IL-8 EIA kit obtained from Beckman Coulter, Cayman Chemical and BD PharMingen, respectively. For the IL-13 ELISA, we used rhIL-13 (Axxora LLC, San Diego, CA, USA), affinity purified anti-human IL-13 (eBioscience) and biotin anti-human IL-13 (eBioscience); the limit of detection was $\sim 5 \mathrm{pg} / \mathrm{ml}$.

\section{Statistics}

Unless otherwise specified, all data are expressed as the mean \pm s.e.m., and the differences were analyzed for statistical significance by one-way ANOVA, the Mann-Whitney $U$-test (two-tailed) or the Student's $t$-test (two-tailed), as indicated.

\section{RESULTS}

Expression of IL-1R1, IL-18R $\alpha$ and T1/ST2 by HUCBMCs

IL-1 can enhance Th2 cytokine secretion by both human and mouse mast cells in vitro, ${ }^{10-12}$ and IL-18 can enhance Th2 cytokine secretion by mouse mast cells. ${ }^{13}$ In accordance with these results, we detected both IL-1R1 and IL-18R $\alpha$ on mouse peritoneal mast cells by FACS analysis (data not shown). HUCBMCs express mRNA for IL-1R $1^{19}$ and, in the HUCBMCs we analyzed using DNA microarrays, levels of mRNA (mean \pm s.e.m. from $4-5$ different batches of HUCBMCs) for IL-18R $\alpha$, IL-18R $\beta$ or T1/ST2 were $2.5 \pm 1.1 \%$ $(n=5), 1.4 \pm 1.1 \%(n=4)$ or $1.7 \pm 0.3 \%(n=5)$, respectively,

Table 1 mRNA expression (\% GAPDH) for IL-1R family molecules in naïve HUCBMCs

\begin{tabular}{lccccc}
\hline HUCBMC number & T1/ST2 & IL-18R $\boldsymbol{\alpha}$ & IL-18R $\boldsymbol{\beta}$ & Fc\&Rl $\boldsymbol{\alpha}$ & C-Kit \\
\hline 1 & 1.1 & 1.4 & 4.5 & 8.1 & 71.0 \\
2 & 1.3 & 3 & 0.3 & 14.5 & 34.7 \\
3 & 1 & 3.4 & 0.1 & 1.6 & 16.6 \\
4 & 2.5 & 1.5 & $\mathrm{ND}$ & $\mathrm{ND}$ & $\mathrm{ND}$ \\
5 & 2.4 & 3.3 & 0.5 & 6.1 & 36.7 \\
\hline
\end{tabular}

HUCBMC, human umbilical cord blood-derived mast cell; ND, not done. mRNA expression in HUCBMCs was analyzed using DNA microarrays and the data were expressed as $\%$ of amounts of GAPDH mRNA in the same populations of cells. of levels of GAPDH mRNA in the same cells (Table 1). By contrast, little or no expression of either IL-1R1 or IL-18R $\alpha$ (IL-1R5) was detectable on the surface of naïve HUCBMCs maintained under the usual conditions of culture (Figure 1).

T1/ST2 (IL-1R4) is considered to be a marker of mouse mast cell progenitors ${ }^{17,21}$ and has been reported to be expressed constitutively on the surface of mouse mast cells. ${ }^{17}$ However, little surface expression of T1/ST2 was detectable on the surface of naïve HUCBMCs (Figure 1). On the other hand, each of these three members of the IL-1R family of cytokines was detected intracellularly in naïve HUCBMCs (Figure 1). Thus, populations of HUCBMCs and mouse mast cells differ in their patterns of surface expression of T1/ST2.

\section{rhIL-1 $\beta$, rhIL-18 or rhIL-33 can Promote Phosphorylation of Erk, p38 and JNK in Naïve HUCBMCs}

IL-33/T1/ST2 signals, like IL-1/IL-1R1 and IL-18/IL-18R signals, are mediated by MyD88, IRAK, IRAK4 and TRAF6 in mouse mast cells, and such signaling is associated with the phosphorylation of MAP kinases in these cells. ${ }^{15}$ While surface expression of IL-1R1, IL-18R $\alpha$ and T1/ST2 was barely detectable on naïve HUCBMCs, we found that rhIL- $1 \beta$, rhIL18 or rhIL-33 promoted Erk, p38 and JNK phosphorylation

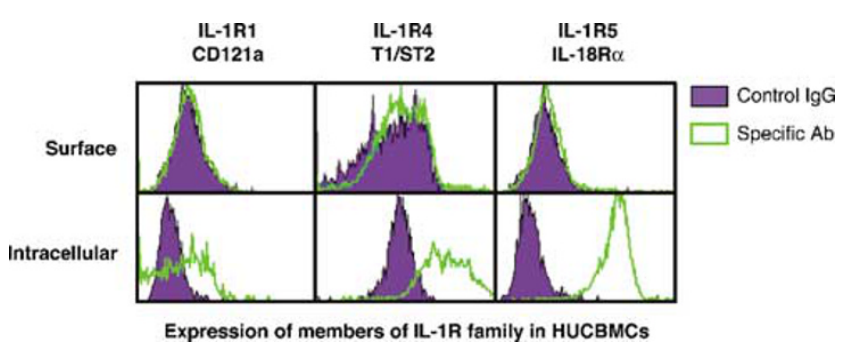

Figure 1 Expression of members of the IL-1R family of cytokines in HUCBMCs. Cell surface and intracellular expression of IL-1R1 (CD121a), IL-1R4 (T1/ST2) and IL-1R5 (IL-18R $\alpha$ ) in naïve HUCBMCs. The data are representative of similar results that were obtained in each of the independent experiments we conducted using at least three different batches of HUCBMCs.

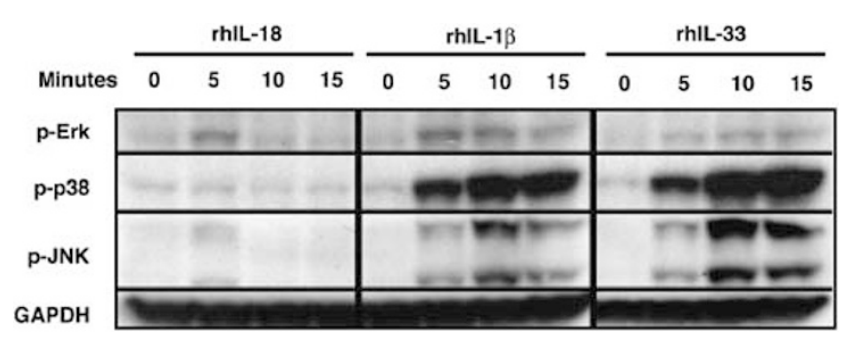

Figure 2 rhIL-1 $\beta$, rhIL-18 or rhIL-33 induce phosphorylation of MAP kinases in naïve HUCBMCs. Naïve HUCBMCs were cultured with $100 \mathrm{ng} / \mathrm{ml}$ of rhlL$1 \beta$, rhlL-18 or rhIL-33 for the indicated time periods. Whole-cell lysates were then prepared and the phosphorylation of MAP kinases was assessed by Western blot analysis. The data are representative of the similar results that were obtained in independent experiments conducted using at least two distinct batches of HUCBMCs for analysis of each cytokine. 
in these HUCBMCs (Figure 2). However, the responses of HUCBMCs to rhIL-18 were considerably weaker than those induced by rhIL-1 $\beta$ or rhIL-33 (Figure 2 ).

\section{rhIL-1 $\beta$ or rhIL-33, but not rhIL-18, can Enhance HUCBMC Survival and Adhesion to Fibronectin}

We next investigated the effects of IL-1 $\beta$, IL-18 and IL-33 on HUCBMC survival and adhesion to fibronectin. When naïve HUCBMCs were cultured after the withdrawal of exogenous rhSCF in the presence of $100 \mathrm{ng} / \mathrm{ml}$ of each of the cytokines, rhIL- $1 \beta$ or rhIL-33, but not rhIL-18, significantly prolonged HUCBMC survival and inhibited their apoptosis (Figure 3a). Moreover, the responses to rhIL-33 were more pronounced than those to rhIL-1 $\beta(P<0.05$ by ANOVA) (Figure $3 a)$.

rhIL-1 $\beta$ or rhIL-33, but not rhIL-18, also enhanced the adhesion of naïve HUCBMCs to fibronectin in the absence of added rhSCF (Figure $3 \mathrm{~b}$ ). Exposure to rhSCF markedly enhanced the adhesion of naive HUCBMCs to fibronectin (Figure 3b), as has been reported by others. ${ }^{22-25}$ Recombinant hIL-33, but neither rhIL-1 $\beta$ nor rhIL-18, also significantly, albeit marginally, enhanced the adhesion of naïve HUCBMCs to fibronectin in the presence of rhSCF (Figure $3 \mathrm{~b}$ ). Although recombinant hIL-1 $\beta$ also appeared to enhance slightly the adhesion of naïve HUCBMCs to fibronectin in the presence of rhSCF, this effect was not statistically significant (Figure $3 \mathrm{~b}$ ).

\section{rhIL-1 $\beta$, rhIL-18 or rhIL-33 does not Induce Secretion of $\mathrm{PGD}_{2}$ or Histamine by HUCBMCs}

None of the cytokines tested detectably induced $\mathrm{PGD}_{2}$ or histamine release by naïve HUCBMCs (see results for 'No IgE' in Figure 4, and data not shown). We previously demonstrated that IgE binding to FceRI without crosslinking by specific Ags or by anti-IgE can enhance cytokine production, but not $\mathrm{PGD}_{2}$ or histamine release, by HUCBMCs. ${ }^{18}$ However, even after the addition of IgE, neither rhIL-1 $\beta$, rhIL-18 nor rhIL-33 had any detectable effect on the release of $\mathrm{PGD}_{2}$ (indicated as ' + IgE' in Figure 4) or histamine (data not shown) from naïve HUCBMCs. As expected, IgE-sensitized HUCBMCs, which were then activated with anti-IgE exhibited release of both $\mathrm{PGD}_{2}$ (Figure 4) and histamine (data not shown); however, the magnitude of such mediator

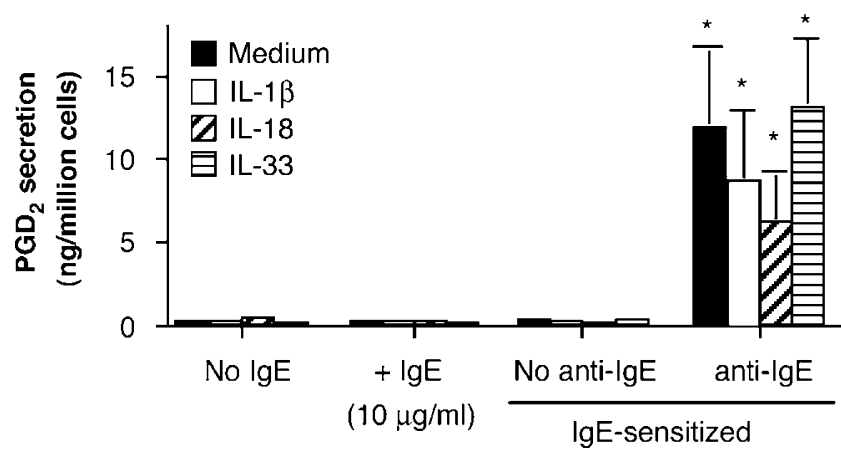

Figure 4 Effects of rhIL- $1 \beta$, rhlL-18 or rhIL-33 on $\mathrm{PGD}_{2}$ secretion by HUCBMCs. Naïve HUCBMCs cultured in the presence $(+\lg E)$ or absence (No $\operatorname{lgE}$ ) of $10 \mu \mathrm{g} / \mathrm{ml}$ of $\operatorname{lgE}$, or IgE-sensitized HUCBMCs cultured in the presence (anti-lgE) or absence (No anti-lgE) of $1 \mu \mathrm{g} / \mathrm{ml}$ of anti-lgE, were cultured with or without $100 \mathrm{ng} / \mathrm{ml}$ of rhlL-1 $\beta$, rhlL-18 or rhIL-33 for $1 \mathrm{~h}$. The amounts of $\mathrm{PGD}_{2}$ in the culture supernatants were quantified by EIA. Data are the average \pm s.e.m. ( $n=4$ /condition) of one determination for each condition for each batch of HUCBMCs, in experiments conducted with four different batches of HUCBMCs. ${ }^{*} P<0.05$ vs corresponding values for the No $\operatorname{lgE}$ condition by Student's $t$-test, two-tailed.
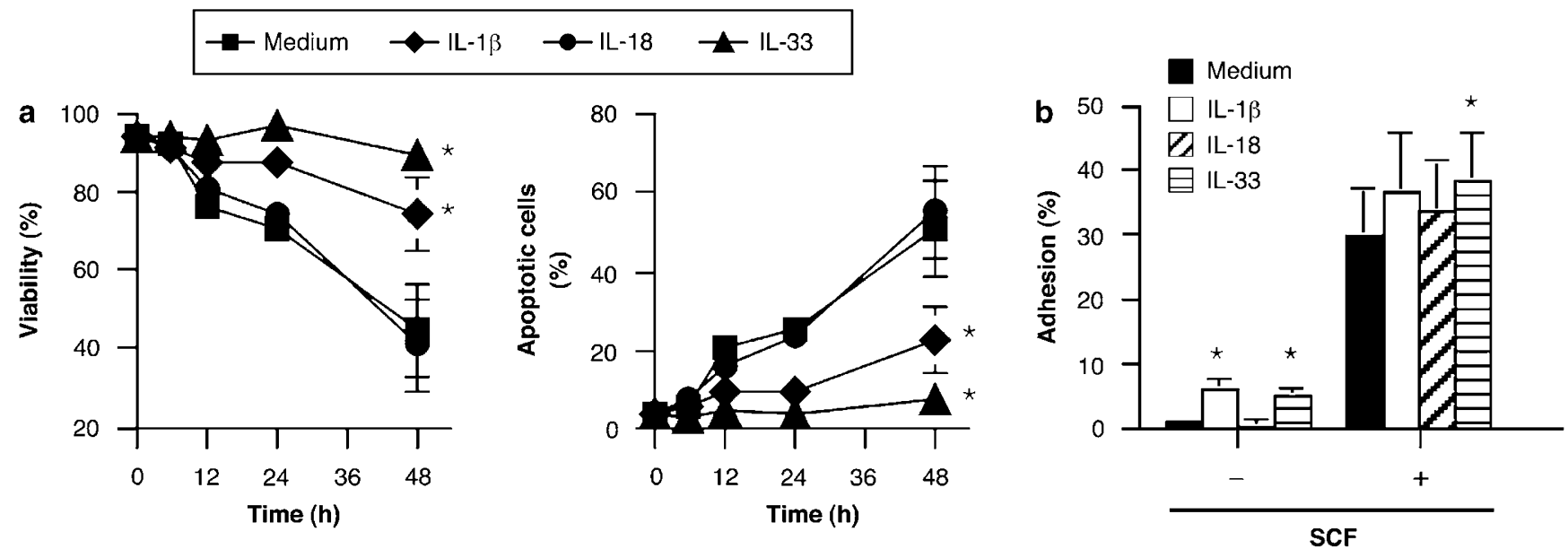

Figure 3 Effects of rhIL-1 $\beta$, rhlL-18 or rhIL-33 on HUCBMC survival, apoptosis and adhesion to fibronectin. (a) Naïve HUCBMCs were cultured with or without $100 \mathrm{ng} / \mathrm{ml}$ rhlL-1 $\beta$, rhlL-18 or rhlL-33 for the indicated time periods. Cell viability was assessed by trypan blue staining using a microscope. Annexin-Vpositive (apoptotic) cells were assessed by FACS analysis. (b) Naïve HUCBMCs were cultured with or without $100 \mathrm{ng} / \mathrm{ml}$ rhIL-1 $\beta$, rhIL-18 or rhIL-33, in the presence $(+)$ or absence $(-)$ of $100 \mathrm{ng} / \mathrm{ml}$ of rhSCF for $1.5 \mathrm{~h}$ in plates coated with fibronectin. The $\%$ of fibronectin-adherent mast cells was assessed as described in Materials and Methods. Data are the average \pm s.e.m. ( $n=4 /$ condition) of one determination for each condition for each batch of HUCBMCs, in experiments conducted with four different batches of HUCBMCs. ${ }^{*} P<0.05$ vs corresponding values at that time point for the Medium alone condition by Student's t-test, two-tailed. 
release was not significantly influenced by the concomitant exposure of the cells to rhIL-1 $\beta$, rhIL-18 or rhIL-33.

\section{rhIL-1 $\beta$ or rhIL-33, but not rhIL-18, can Promote IL-8 and IL-13 Secretion by HUCBMCs}

It has been reported that rIL-18 can induce the production of the Th2 cytokines, IL- 4 and IL-13, by mouse mouse bone marrow cell-derived cultured mast cells (BMCMCs) in the presence of certain second signals, namely, rIL-3 or IgE plus anti-IgE. ${ }^{13}$ Therefore, we investigated whether rhIL-1 $\beta$, rhIL18 or rhIL-33 influenced the production of cytokines by HUCBMCs.

We found that rhIL-1 $\beta$ or rhIL-33, but not rhIL-18, directly enhanced IL-8 production by naïve HUCBMCs (indicated as 'No IgE' in Figure 5). At the highest concentration tested $(100 \mathrm{ng} / \mathrm{ml})$, rhIL-33 also induced IL-13 secretion by naïve HUCBMCs (Figure 4). Although rhIL-1 $\beta$ slightly but significantly enhanced IL-13 production by naïve HUCBMCs (at $100 \mathrm{ng} / \mathrm{ml}$, rhIL-1 $\beta$ induced naïve HUCBMCs to produce $11.4 \mathrm{pg}$ IL-13/million cells $v s 1.6 \mathrm{pg} /$ million cells in the absence of cytokine stimulation), this effect was substantially weaker than that of rhIL-33 (see 'No IgE' in Figure 5).

As expected, crosslinking of IgE-FceRI by anti-IgE induced the secretion of IL-8 by HUCBMCs, whereas the amount of IL-13 in the supernatants was below the limit of detection
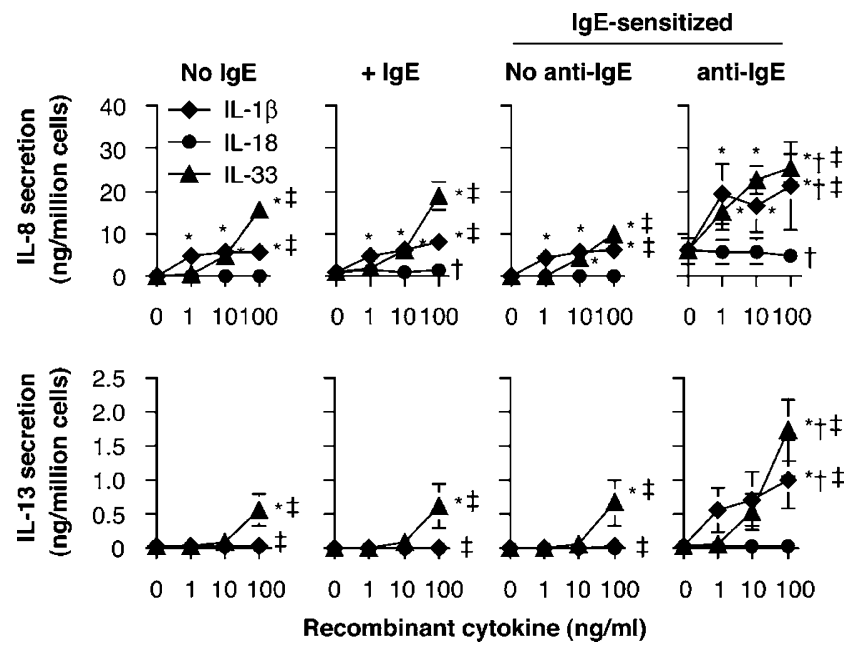

Figure 5 IL-33 can induce IL-13 production by naïve HUCBMCs independently of $\operatorname{IgE}-\mathrm{Fc} \varepsilon \mathrm{R}$ signals. Naïve HUCBMCs cultured in the presence $(+\lg \mathrm{E}$ ) or absence (No $\lg \mathrm{E})$ of $10 \mu \mathrm{g} / \mathrm{ml}$ of $\lg \mathrm{E}$, or $\lg \mathrm{E}-$ sensitized HUCBMCs (which had been incubated with $10 \mu \mathrm{g} / \mathrm{ml} \mathrm{lgE}$ for $4 \mathrm{~h}$, and then washed) cultured in the presence (anti-IgE) or absence (No anti-IgE) of $1 \mu \mathrm{g} /$ $\mathrm{ml}$ of anti-lgE, were cultured with or without various concentrations of rhIL$1 \beta$, rhlL-18 or rhIL-33 for $24 \mathrm{~h}$. The amounts of IL- 8 and IL-13 in the culture supernatants were measured by ELISA. Data are the average \pm s.e.m. ( $n=5 /$ condition) of one determination for each condition for each batch of HUCBMCs, in experiments conducted with five different batches of HUCBMCs. ${ }^{*} P<0.05$ vs corresponding values for no recombinant cytokine $(0 \mathrm{ng} / \mathrm{ml})$ by Student's $t$-test (two-tailed); ${ }^{\ddagger} P<0.05$ vs corresponding values for the cells cultured with rhIL-18 by ANOVA; ${ }^{\dagger} P<0.05$ vs corresponding values for the cells cultured without any stimuli (No IgE) by ANOVA. $(\sim 1 \mathrm{pg} / \mathrm{ml})$ of our ELISA (Figure 5$)$. In HUCBMCs subjected to crosslinking of IgE-Fc\&RI by anti-IgE, rhIL-1 $\beta$ or rhIL-33, but not rhIL-18, dose dependently induced detectable secretion of IL-13, and also markedly and dose dependently enhanced IL-8 secretion (Figure 5). As previously reported ${ }^{18}$ we found that IgE alone, in the absence of either added specific Ag or IL-1 family cytokines, also induced release of IL-8 $(0.9 \pm 0.8 \mathrm{ng} /$ million cells with $\operatorname{IgE}$ alone $(+\operatorname{IgE}$ in Figure 5) vs $0.1 \pm 0 \mathrm{ng} /$ million cells in the absence of IgE (No IgE in Figure 5), $P<0.02$ by Mann-Whitney $U$-test).

As shown in Figure 2, exposure to either IL-33 or IL-1 $\beta$ induced p38 phosphorylation in HUCBMCs. This suggested that IL-33-induced IL-8 production by HUCBMCs, like IL$1 \beta$-induced secretion of IL- 6 in such cells, ${ }^{20}$ was mediated by a signaling pathway involving p38 MAPK. Indeed, we found that IL-1 $\beta$-, IL-33- or IgE and anti-IgE-induced IL-8 production by HUCBMCs was dramatically reduced by the addition of the p38 MAPK inhibitor, SB203580 (Figure 6a), at concentrations that did not significantly reduce HUCBMC viability (Figure 6b).

Taken together, our results indicate that rhIL-1 $\beta$ or rhIL-33 can enhance human mast cell functions in vitro, including survival after withdrawal of exogenous SCF, adhesion to fibronectin and ability to secrete IL-8 and IL-13. On the other hand, in contrast to our findings with BMCMCs (Ho et al, submitted), we found that IL-18 exerted no detectable effects on these responses in HUCBMCs.
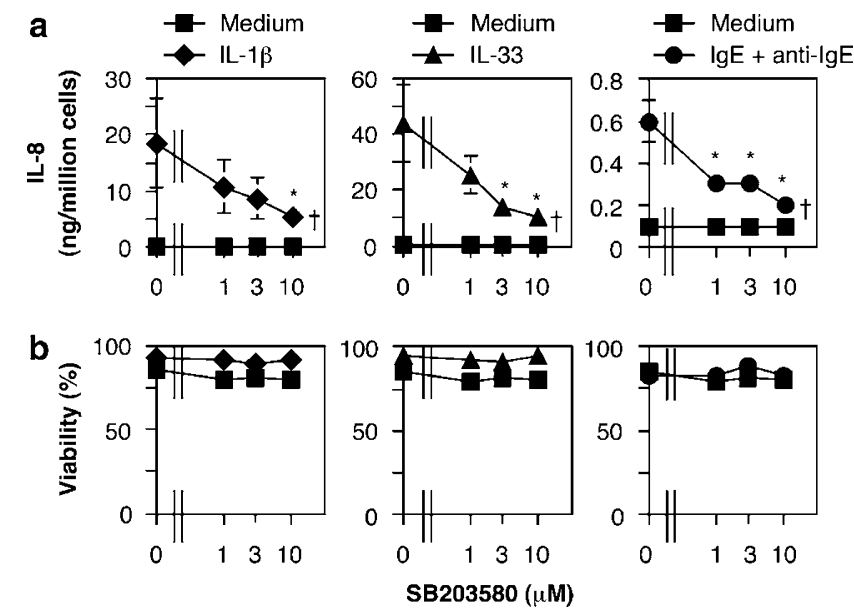

Figure 6 The p38 inhibitor SB203580 reduces IL-33-mediated IL-8 production by naïve HUCBMCs. Naïve or lgE-sensitized ( $1 \mu \mathrm{g} / \mathrm{ml}$, overnight) HUCBMCs $\left(1 \times 10^{6}\right.$ cells $\left./ \mathrm{ml}\right)$ were treated with various concentrations of SB203580 for $30 \mathrm{~min}$, washed, stimulated with or without $100 \mathrm{ng} / \mathrm{ml} \mathrm{rhlL}-1 \beta$ or rhlL-33, or in the presence of $1 \mu \mathrm{g} / \mathrm{ml}$ anti-lgE Ab, respectively, for $24 \mathrm{~h}$, and the amounts of IL- 8 in the culture supernatants were measured by ELISA (a) and cell viability was assessed by trypan blue staining (b). Data are the average \pm s.e.m. ( $n=3 /$ condition) of one determination for each condition for each batch of HUCBMCs in experiments conducted with three different batches of HUCBMCs. ${ }^{\dagger} P<0.05$ vs corresponding values for medium alone (ANOVA). ${ }^{*} P<0.05$ vs corresponding values for no SB203580 $(0 \mu \mathrm{M})$ (Mann-Whitney U-test). 


\section{DISCUSSION}

We found that IL-1 $\beta$ or IL-33 enhanced HUCBMC survival, adhesion to fibronectin and cytokine production. However, in contrast to findings with mouse mast cells, IL-18 did not significantly influence these responses in HUCBMCs. Thus, taken together with the results of our own recent study of the effects of IL-1 $\beta$, IL-18 and IL-33 in mouse bone marrow cellderived cultured mast cells (BMCMCs) (Ho et al, submitted), it appears that human and mouse mast cells can differ in their responses to exposure to individual members of the IL-1 family of cytokines.

Our findings with IL- $1 \beta$ support the conclusions of prior in vitro studies, which indicated that, under certain circumstances, IL-1 can influence human mast cell activation. For example, IL-1 has been reported to enhance histamine release by human adenoidal mast cells independently of $\operatorname{IgE}-\mathrm{Fc} \varepsilon \mathrm{RI}$ signals. ${ }^{26}$ While IL-1 did not directly induce the release of $\mathrm{PGD}_{2}$ or $\mathrm{LTC}_{4}$ from human lung mast cells, it did enhance the release of these mediators in the presence of $\operatorname{IgE}-\mathrm{F} c \varepsilon \mathrm{RI}$ signals. ${ }^{27}$ Moreover, it has been reported that when tested in the presence of SCF, IL- 1 can promote IL-6 production (but not degranulation) in either HUCBMCs or a human leukemic mast cell line (HMC-1) even in the absence of IgEFceRI signals, ${ }^{20,28}$ and that such IL-1-induced secretion of IL6 by HUCBMCs was significantly reduced by an inhibitor of p38 MAPK. ${ }^{20}$ IL-1 can also directly induce the production of MCP-1 by HUCBMCs or HMC- 1 cells, ${ }^{10}$ and can enhance IL-13 production by these cells in the presence of IgE-FceRImediated stimulation. ${ }^{10}$

We observed that rhIL-1 $\beta$ directly enhanced the survival, adhesion to fibronectin and IL-8 secretion of HUCBMCs and enhanced IL-13 secretion, but not histamine or $\mathrm{PGD}_{2}$ release, in the presence of IgE-FceRI-mediated stimulation. Moreover, as was reported for IL-1-induced IL- 6 secretion by HUCBMCs, ${ }^{20}$ we found that IL-33 (as well as IL-1)-induced secretion of IL-8 from HUCBMCs was markedly reduced when the cells were treated with the p38 MAPK inhibitor, SB203580. However, in contrast to results reported by Subramanian and Bray $^{26}$ (who analyzed human adenoidal or lung mast cells, respectively), but consistent with the observations of Kandere-Grzybowska et $a^{28}$ (who analyzed both HUCBMCs and HMC-1), we found that rhIL-1 did not directly induce mast cell degranulation, as assessed in our study by release of histamine. It is possible that some of the differences in the results obtained by the various groups that tested the effects of IL-1 on human mast cells reflect phenotypic differences in the human mast cell populations tested (which were derived from distinct tissues or were maintained under different culture conditions), since it is known that different populations of human mast cells can exhibit differences in phenotype and function. ${ }^{29}$

IL-18 was originally identified as an IFN- $\gamma$-inducible factor, and was shown to enhance Th1 and Th17 cell differentiation and IFN- $\gamma$ and IL-17 production. $^{30,31}$ Both immature IL-1 $\beta$ and immature IL-18 are cleaved by caspase-
1,32 and the mature forms of IL- $1 \beta$ and IL- 18 can be secreted by several different cell types, including macrophages, dendritic cells and keratinocytes. ${ }^{30}$ Like IL-18, IL-1 $\beta$ also was found to enhance Th1 and Th17 cell differentiation and IFN$\gamma$ and IL-17 production, both in human ${ }^{33}$ and mouse ${ }^{31,34} \mathrm{~T}$ cells. These findings raised the possibility that IL-18 and IL-1 might have similar effects on mast cells. Indeed, IL-18 has been shown to promote IL- 4 and IL- 13 production by mouse mast cells in the presence of IL-3 or IgE-Fc $\&$ RImediated stimulation. ${ }^{13}$ We found that IL-18 can promote IL- 6 and IL-13 secretion in mouse BMCMCs that had been exposed to a highly cytokinergic mouse IgE (SPE-7 IgE) in the absence of known Ag recognized by that $\operatorname{IgE}$ (Ho et al, submitted).

Taken together, these observations in mice suggest that IL18 may contribute to the development of certain allergic diseases in humans, such as atopic dermatitis, in part through effects on mast cells. However, in contrast to our observations with rhIL- $1 \beta$, we found that rhIL-18 did not significantly enhance HUCBMC survival upon withdrawal of exogenous SCF or promote the adhesion of HUCBMCs to fibronectin. Nor did rhIL-18 induce or enhance histamine or $\mathrm{PGD}_{2}$ release or production of IL- 8 or IL-13, either in the presence or absence of IgE-FceRI-mediated stimulation. We did find that rhIL-18 promoted phosphorylation of MAP kinases in naïve HUCBMCs, but this effect was much weaker than that observed when the cells were exposed to or rhIL-1 $\beta$ or rhIL-33 (Figure 2). Thus, our findings with HUCBMCs (this study) and mouse BMCMCs (Ho et al, submitted) indicate that IL-18 has distinct effects on the mouse $v s$ human mast cell populations tested.

IL-33 (also called NF-HEV or DVS27) is one of the more recently identified members of the IL-1 family of cytokines. ${ }^{15}$ IL-33 expression has been identified in skeletal muscle cells and in airway epithelia, ${ }^{35}$ and IL-33 expression can be upregulated by IL-1 in arterial smooth muscle cells and the lung, as well as in dermal fibroblasts and keratinocytes. ${ }^{15,35}$ IL-33 also has been demonstrated to induce the activation of mouse Th2 cells and mast cells, via effects mediated by the IL-33 receptor, T1/ST2/IL-R4. ${ }^{15}$

In mice, T1/ST2/IL-R4 is preferentially expressed on Th2 cells ${ }^{16}$ and mast cells. ${ }^{17}$ Indeed, T1/ST2 represents a lineage marker for mast cell precursors in the mouse, ${ }^{17,21}$ and is strongly and constitutively expressed on naïve mouse BMCMCs $^{17}$ (Ho et al, submitted). In contrast to findings in mouse mast cells, we found that surface expression of T1/ST2 was hardly detectable on naïve HUCBMCs, although substantial amounts of intracellular T1/ST2 was identifiable in these cells (Figure 1a). Despite the low levels of surface expression of T1/ST2 on naive HUCBMCs, we found that IL-33 can influence multiple aspects of the biology of these cells. Specifically, IL-33 enhanced the survival of HUCBMCs after withdrawal of exogenous SCF, promoted the adhesion of such cells to fibronectin and enhanced the cells' ability to secrete IL-8 and IL-13. 
In addition to enhancing IL-8 and IL-13 production in HUCBMCs which also had been stimulated via aggregation of the FceRI, IL-33 induced HUCBMCs to secrete IL- 8 and IL-13 directly, that is, in the absence of co-stimulation via either the Fc\&RI or by other exogenous stimuli, such as agonists of TLRs (the preparations of recombinant cytokines contained $<1.0 \mathrm{EU} / \mu \mathrm{g}$, as assessed by the limulus assay). In our study of mouse BMCMCs (Ho et al, submitted), we found that rmIL-33 can directly induce the release of IL-6 and IL-13 from mouse mast cells in the absence of co-stimulation via the Fc\&RI. To the best of our knowledge, there have been no previous reports of cytokines, which can directly induce IL-13 production by mast cells of any species.

Our work was conducted using in vitro systems, and one should be very cautious in attempting to extrapolate from such findings to settings in vivo. Nevertheless, it is tempting to speculate about some of the potential implications of our findings. Several lines of evidence support the hypothesis that IL- $1 \beta$ and IL-33 and their receptors may contribute to pathology in allergic disorders at least in part via effects on mast cells. For example, soluble forms of cytokine receptors, such as those for IL-1, can act as an inhibitors for their ligands, and increased concentrations of such soluble receptors have been reported during inflammatory processes. ${ }^{36}$ However, soluble cytokine receptors such as these also have been shown to exhibit agonistic activity in some cases. ${ }^{37}$ Like levels of the soluble form of IL-1Rs, levels of soluble T1/ST2 are increased in inflammation, and serum levels of soluble T1/ST2 have been shown both to be increased in patients with asthma and to exhibit a positive correlation with the severity of the condition. ${ }^{38}$ In addition, it has been reported that a singlenucleotide polymorphism in the region of the promoter of the $t 1 / s t 2$ gene may influence susceptibility to atopic dermatitis in humans. ${ }^{39}$

Since the secretion of IL-33, as well as IL- $1 \beta$ and IL-18, is caspase-1 cleavage-dependent ${ }^{15}$ in the mouse, the development of dermatitis in keratinocyte-specific caspase-1-overexpressing transgenic mice ${ }^{40}$ may reflect, at least in part, the overproduction of IL-33, IL-1 $\beta$ and IL-18. Moreover, either IL- $1 \alpha$ or IL- $1 \beta$ can upregulate IL-33 expression in arterial smooth muscle cells and in dermal fibroblasts and keratinocytes. ${ }^{15,35}$ We demonstrated that while IL- $1 \beta$ did not directly induce IL-13 production by naïve HUCBMCs, it did promote human mast cell survival and adhesion. Thus, IL$1 \beta$, by enhancing production of IL-33 by keratinocytes, airway epithelial cells, smooth muscle cells and/or other cell types, may indirectly promote mast cell secretion of IL-13 in such settings, even in the absence of co-stimulation of mast cells by aggregation of the Fc\&RI. This, in turn, may contribute to the pathology of allergic disorders such as atopic asthma and dermatitis. It of course will be of interest to investigate these possibilities directly, as the results of such studies may provide clues for the development of novel therapies for mast cell-associated allergic disorders.

\section{ACKNOWLEDGEMENTS}

We thank all the members of the Galli and the Saito laboratories for their helpful discussions, Keisuke Yuki for technical assistance, and Amgen Inc., Thousand Oaks, CA, for the generous gifts of rhSCF and rhlL-6. This work was supported by a Grant ID 05-24 from National Institute of Biomedical Innovation (to H Saito) and by United States Public Health Service Grants HL-67674, Al-23990, Al-070813 and CA-72074 (to SJG).

1. Marshall JS. Mast-cell responses to pathogens. Nat Rev Immunol 2004;4:787-799.

2. Galli SJ, Nakae S, Tsai M. Mast cells in the development of adaptive immune responses. Nat Immunol 2005;6:135-142.

3. Metzger $\mathrm{H}$. The receptor with high affinity for IgE. Immunol Rev 1992;125:37-48.

4. Metcalfe DD, Baram D, Mekori YA. Mast cells. Physiol Rev 1997;77:1033-1079.

5. Turner $\mathrm{H}$, Kinet JP. Signalling through the high-affinity IgE receptor FceRI. Nature 1999;402:B24-B30.

6. Kawakami T, Galli SJ. Regulation of mast-cell and basophil function and survival by IgE. Nat Rev Immunol 2002;2:773-786.

7. Rivera J. Molecular adapters in $\mathrm{Fc} \& \mathrm{RI}$ signaling and the allergic response. Curr Opin Immunol 2002;14:688-693.

8. Gould HJ, Sutton BJ, Beavil AJ, et al. The biology of IgE and the basis of allergic disease. Annu Rev Immunol 2003;21:579-628.

9. Galli SJ, Kalesnikoff J, Grimbaldeston MA. et al. Mast cells as 'tunable' effector and immunoregulatory cells: recent advances. Annu Rev Immunol 2005;23:749-786.

10. Lee SA, Fitzgerald SM, Huang SK, et al. Molecular regulation of interleukin-13 and monocyte chemoattractant protein-1 expression in human mast cells by interleukin-1 $\beta$. Am J Respir Cell Mol Biol 2004;31:283-291.

11. Stassen M, Arnold M, Hultner L. et al. Murine bone marrow-derived mast cells as potent producers of IL-9: costimulatory function of IL-10 and kit ligand in the presence of IL-1. J Immunol 2000;164:5549-5555.

12. Hultner $L$, Kolsch $S$, Stassen $M$, et al. In activated mast cells, IL-1 upregulates the production of several Th2-related cytokines including IL-9. J Immunol 2000;164:5556-5563.

13. Yoshimoto $T$, Tsutsui $H$, Tominaga $K$, et al. IL-18, although antiallergic when administered with IL-12, stimulates IL- 4 and histamine release by basophils. Proc Natl Acad Sci USA 1999;96:13962-13966.

14. Sims JE, Nicklin MJ, Bazan JF, et al. A new nomenclature for IL-1-family genes. Trends Immunol 2001;22:536-537.

15. Schmitz J, Owyang A, Oldham E, et al. IL-33, an interleukin-1-like cytokine that signals via the IL-1 receptor-related protein ST2 and induces T helper type 2-associated cytokines. Immunity 2005;23: 479-490.

16. Lohning $M$, Stroehmann $A$, Coyle $A J$, et al. $T 1 / S T 2$ is preferentially expressed on murine Th2 cells, independent of interleukin 4, interleukin 5, and interleukin 10, and important for Th2 effector function. Proc Natl Acad Sci USA 1998;95:6930-6935.

17. Moritz DR, Rodewald HR, Gheyselinck J, et al. The IL-1 receptor-related $\mathrm{T} 1$ antigen is expressed on immature and mature mast cells and on fetal blood mast cell progenitors. J Immunol 1998;161:4866-4874.

18. Matsuda K, Piliponsky AM, likura M, et al. Monomeric IgE enhances human mast cell chemokine production: IL-4 augments and dexamethasone suppresses the response. J Allergy Clin Immunol 2005;116:1357-1363.

19. Nakajima T, Inagaki $\mathrm{N}$, Tanaka $\mathrm{H}$. et al. Marked increase in CC chemokine gene expression in both human and mouse mast cell transcriptomes following Fcepsilon receptor I crosslinking: an interspecies comparison. Blood 2002;100:3861-3868.

20. Kandere-Grzybowska K, Kempuraj D, Cao J. et al. Regulation of IL-1induced selective IL- 6 release from human mast cells and inhibition by quercetin. Br J Pharmacol 2006;148:208-215.

21. Chen CC, Grimbaldeston MA, Tsai M, et al. Identification of mast cell progenitors in adult mice. Proc Natl Acad Sci USA 2005;102: 11408-11413.

22. Kinashi T, Springer TA. Steel factor and c-kit regulate cell-matrix adhesion. Blood 1994;83:1033-1038.

23. Dastych J, Metcalfe DD. Stem cell factor induces mast cell adhesion to fibronectin. J Immunol 1994;152:213-219. 
24. Nilsson G, Butterfield $\mathrm{JH}$, Nilsson K. et al. Stem cell factor is a chemotactic factor for human mast cells. J Immunol 1994;153: 3717-3723.

25. Lorentz A, Schuppan D, Gebert A, et al. Regulatory effects of stem cell factor and interleukin-4 on adhesion of human mast cells to extracellular matrix proteins. Blood 2002;99:966-972.

26. Subramanian N, Bray MA. Interleukin 1 releases histamine from human basophils and mast cells in vitro. J Immunol 1987;138:271-275.

27. Salari H, Chan-Yeung M. Interleukin-1 potentiates antigen-mediated arachidonic acid metabolite formation in mast cells. Clin Exp Allergy 1989;19:637-641.

28. Kandere-Grzybowska K, Letourneau R, Kempuraj D, et al. IL-1 induces vesicular secretion of IL- 6 without degranulation from human mast cells. J Immunol 2003;171:4830-4836.

29. Kashiwakura J, Yokoi $H$, Saito $H$, et al. T cell proliferation by direct cross-talk between OX40 ligand on human mast cells and OX40 on human T cells: comparison of gene expression profiles between human tonsillar and lung-cultured mast cells. J Immunol 2004;173:5247-5257.

30. Nakanishi $\mathrm{K}$, Yoshimoto $\mathrm{T}$, Tsutsui $\mathrm{H}$, et al. Interleukin-18 regulates both Th1 and Th2 responses. Annu Rev Immunol 2001;19:423-474.

31. Nakae $S$, Iwakura $Y$, Suto $H$, et al. Phenotypic differences between Th1 and Th17 cells and negative regulation of Th1 cell differentiation by IL-17. J Leukoc Biol 2007;81:1258-1268.

32. Fantuzzi G, Dinarello CA. Interleukin-18 and interleukin-1 $\beta$ : two cytokine substrates for ICE (caspase-1). J Clin Immunol 1999;19:1-11.
33. Tominaga $\mathrm{K}$, Yoshimoto $\mathrm{T}$, Torigoe $\mathrm{K}$, et al. IL-12 synergizes with IL-18 or IL-1 $\beta$ for IFN- $\gamma$ production from human T cells. Int Immunol 2000;12:151-160.

34. Shibuya K, Robinson D, Zonin F, et al. IL- $1 \alpha$ and TNF- $\alpha$ are required for IL-12-induced development of Th1 cells producing high levels of IFN- $\gamma$ in BALB/C but not C57BL/6 mice. J Immunol 1998;160:1708-1716.

35. Onda $\mathrm{H}$, Kasuya $\mathrm{H}$, Takakura $\mathrm{K}$, et al. Identification of genes differentially expressed in canine vasospastic cerebral arteries after subarachnoid hemorrhage. J Cereb Blood Flow Metab 1999;19: 1279-1288.

36. Sims JE, Giri JG, Dower SK. The two interleukin-1 receptors play different roles in IL-1 actions. Clin Immunol Immunopathol 1994;72: 9-14.

37. Sporri B, Bickel M, Dobbelaere D, et al. Soluble interleukin-1 receptorreverse signaling in innate immunoregulation. Cytokine Growth Factor Rev 2001;12:27-32.

38. Oshikawa K, Kuroiwa K, Tago K, et al. Elevated soluble ST2 protein levels in sera of patients with asthma with an acute exacerbation. Am J Respir Crit Care Med 2001;164:277-281.

39. Shimizu M, Matsuda A, Yanagisawa $K$, et al. Functional SNPs in the distal promoter of the ST2 gene are associated with atopic dermatitis. Hum Mol Genet 2005;14:2919-2927.

40. Konishi $\mathrm{H}$, Tsutsui $\mathrm{H}$, Murakami $\mathrm{T}$. et al. IL-18 contributes to the spontaneous development of atopic dermatitis-like inflammatory skin lesion independently of IgE/stat6 under specific pathogen-free conditions. Proc Natl Acad Sci USA 2002;99:11340-11345. 